\section{Considerações bioéticas sobre os modelos de assistência no fim da vida}

\author{
Bioethical considerations on models for \\ end-of-life care
}

\section{Consideraciones bioéticas sobre los modelos de asistencia al fin de la vida}

\section{Resumo}

Este artigo discute os três campos assistenciais institucionalizados nas sociedades contemporâneas para cuidados no fim da vida e seus respectivos modelos de morte: a eutanásia/suicídio assistido; a futilidade médica; e a kalotanásia, fundamento do moderno movimento hospice. Analisa, também, de que modo estes modelos impactam a vida dos pacientes, bem como a fragilidade conceitual de algumas das bandeiras tradicionalmente utilizadas, como a da dignidade humana. São feitas, também, considerações à ortotanásia, conceito muito utilizado na literatura bioética nacional, bem como ao suicídio racional nos idosos. Além disso, propõem-se questões para o debate bioético acerca da necessidade de serem repensados, em nosso meio, alguns postulados, especialmente aqueles referentes à eutanásia. Por último, apresenta e analisa a fundamentação ética e filosófica da kalotanásia e suas implicações para a organização de boas práticas de cuidados no fim da vida.

Bioética; Atitude Frente a Morte; Futilidade Médica; Eutanásia; Cuidados Paliativos
Ciro Augusto Floriani 1

doi: 10.1590/0102-311X00264320

\author{
Correspondência \\ C. A. Floriani \\ Rua Dr. Herotides de Oliveira 44, apto. 1003, Niterói, RJ \\ 24230-230, Brasil. \\ ciroafloriani@gmail.com \\ 1 Faculdade de Medicina Estácio de Sá, Rio de Janeiro, Brasil.
}




\section{Introdução}

A construção e organização de modelos assistenciais que incluam adequada e compassiva abordagem aos pacientes com doenças avançadas e em fase terminal implicam, necessariamente, na capacitação de recursos humanos competentes, tanto do ponto de vista ético quanto técnico. Implicam, outrossim, em conscientizar e dar condições aos gestores do campo sanitário, quer sejam públicos ou privados, para essa construção e organização. Isso significa criar uma concreta política nacional de assistência no fim da vida, não só com relação a uma busca de melhor qualidade de vida, mas na oferta de melhor qualidade de morte a esses pacientes. Chama a atenção, nesse sentido, a não contemplação dos cuidados no fim da vida tanto na Política Nacional do Idoso quanto no Estatuto do Idoso, a despeito de ser esta faixa etária bastante atingida por este tema. Trata-se de um problema ético e de saúde pública que precisa ser amplamente enfrentado e discutido.

E por que se deve investir em qualidade de morte quando tanto se fala em qualidade de vida? Não seriam, intuitivamente, dois campos antinômicos? Não seria estranho falar em qualidade de morte justo quando os estupendos avanços biotecnocientíficos dos últimos pelo menos cinquenta anos organizam um cenário médico de intervenções tão promissoras? Para responder a essas questões, vários imperativos morais poderiam ser invocados. Contudo o princípio da dignidade humana, a despeito de ser conceitualmente difuso e heterogêneo, é muito utilizado na reflexão acerca das consequências deletérias ao se romperem os limites da razoabilidade das intervenções terapêuticas aplicadas a um paciente com doença avançada e terminal 1 , as quais se mostram frequentemente obstinadas e, portanto, muito mais próximas da maleficência do que da beneficência. Paciente este que se encontra em um estado de vulneração e de desproteção, com sofrimento desproporcional, muitas vezes com somente uma vida biológica (zoé) disponível, em detrimento de uma vida de plenitude afetiva, social e existencial (bios), com impacto significativo não somente a ele, mas a seu entorno familiar e ao próprio sistema de saúde.

O conceito da boa morte, no contexto dos cuidados no fim da vida, tem sido proposto quando estão presentes determinadas características, tais como: morte sem dor; morte ocorrendo com os desejos do paciente sendo respeitados (verbalizados ou registrados nas diretivas antecipadas de vontade); morte em casa, cercado pelos familiares e amigos; ausência de evitável infortúnio e sofrimento para o paciente, sua família e o cuidador; morte em um contexto onde as pendências do paciente estejam resolvidas e ocorrendo com uma boa relação entre o paciente e sua família com os profissionais de saúde. Entretanto há de se considerar as condições nas quais o paciente enfrenta sua morte, evitando-se, com isso, falsas expectativas acerca desse processo, nem devem ser desconsiderados os aspectos culturais específicos nos quais ele está inserido, especialmente em se tratando de sociedades que se pretendem pluralistas, nas quais há diferentes concepções do que seja uma boa morte 2 .

Este artigo discute os três campos assistenciais institucionalizados nas sociedades contemporâneas e seus respectivos modelos de morte: a eutanásia/suicídio assistido; a futilidade médica; e a kalotanásia, fundamento do moderno movimento hospice. Analisa de que modo esses modelos impactam a vida dos pacientes, bem como as ambiguidades e a fragilidade conceitual de algumas das bandeiras tradicionalmente utilizadas, como a da dignidade humana. Serão feitas, também, considerações à ortotanásia, conceito muito utilizado na literatura bioética nacional contemporânea, bem como ao suicídio racional nos idosos. Além disso, propõe questões para o debate bioético acerca da necessidade de serem repensados alguns postulados, especialmente aqueles referentes à eutanásia. Por último, apresenta e analisa a fundamentação ética e filosófica da kalotanásia e suas implicações para a organização de boas práticas de cuidados no fim da vida.

\section{Assistência na morte e no morrer}

A sociedade ocidental construiu, nos últimos séculos, uma relação de evitamento para com tudo que possa lembrar a morte, em especial a morte por doença natural, isolando-a, de modo progressivo, de nossa convivência cotidiana, sendo esse processo mais nitidamente observado a partir do final do século XIX ${ }^{3}$. Transformação abrupta que em algumas décadas mudou para um modo secular de 
relacionamento da sociedade com a morte e seus rituais. Com efeito, "a morte, tão presente no passado, de tão familiar, vai se apagar e desaparecer. Torna-se vergonhosa e objeto de interdição" 4 (p. 84).

De fato, a partir da Primeira Guerra Mundial, ocorre uma progressiva interdição do luto e de tudo que lembrasse a morte publicamente; porém com esta ainda ocorrendo em casa e com a preservação dos momentos derradeiros e as cenas de despedida, para, a partir de 1945 - com a crescente incorporação da tecnologia às ações médicas, e tendo a "segurança moral do hospital" 3 (p. 640) como o local de excelência desta intervenção - instalar-se a total medicalização da morte. A partir deste período, as mortes ocorrem, em sua expressiva maioria, no hospital, longe da presença das pessoas mais queridas do paciente e do seu núcleo de convivência, e próxima de todo o aparato médico disponível. Estabelece-se, assim, o "triunfo da medicalização: (...) o modelo mais recente da morte está ligado à medicalização da sociedade, isto é, a um dos setores da sociedade industrial onde o poder da técnica foi mais bem-acolhido e ainda é menos contestado" 3 (p. 637; 647).

Para Norbert Elias 5, também contribui para este isolamento dos doentes - pelo menos nas sociedades industriais desenvolvidas - o que ele descreve como sendo um estado de ânimo antipático e silencioso em relação a quem está morrendo e a tudo o que possa lembrar esse processo de morte. Elias acredita que este sentimento de antipatia surgiu em razão de certo estado de pacificação interna e de contenção e devido, também, a uma maior dificuldade de reação dessas sociedades à violência.

\section{O problema da dignidade humana}

A partir da década de 1960, surgem vozes que denunciam o desconforto com o modo como têm sido tratados os pacientes com doenças avançadas, frequentemente abandonados por seus médicos e vivendo seus últimos momentos no isolamento e na frieza de um pronto-socorro, de um quarto ou em uma unidade de terapia intensiva (UTI), muitas vezes cercados por tubos e aparelhos - e não por pessoas próximas e queridas a este paciente. Como bem assinalou Elias 5 (p. 98): "nunca antes as pessoas morreram tão silenciosas e higienicamente como hoje nessas sociedades, e nunca em condições tão propícias à solidão". Por isso começa a emergir a reivindicação da "morte digna", principalmente nos países anglo-saxões 6,7. De acordo com Clark 8, na Grã-Bretanha, berço do moderno movimento hospice, esta reivindicação surgiu mais em face das constatações de abandono dos pacientes pelos seus médicos, enquanto, nos Estados Unidos, o uso frequente da tecnologia para perpetuar a vida foi o motivador maior. Entretanto, de acordo com Ariès 3 (p. 643-4): "a questão essencial é a dignidade da morte. Essa dignidade exige, em primeiro lugar, que a morte seja reconhecida não apenas como um estado real, mas como um acontecimento essencial, que não se permite escamotear. Uma das condições essenciais desse reconhecimento é que o moribundo seja informado do seu estado (...) estaremos nós, portanto, às vésperas de uma mudança nova e profunda diante da morte? A regra do silêncio estaria começando a se tornar caduca?".

A questão da morte digna é, de fato, bastante evocada nos cuidados no fim da vida 9,10, ainda que muitas vezes sem uma definição mais precisa de seu significado. Mas, a despeito dessa imprecisão, é bastante razoável que o tema da dignidade - do latim dignitas, valor, merecimento - seja evocado quando o assunto é o fim da vida, a morte, o morrer e quando se fala de boa morte.

Para Bayertz 11, a dignidade humana tem respaldo em duas fontes de autoridade: a primeira diz respeito à sua raiz que, pelo menos em parte, está centrada na ideia cristã de imago dei; e a segunda, nas leis de várias nações e nas leis internacionais. $\mathrm{O}$ autor destaca que se trata de um termo controverso dentro da Filosofia, devido ao fato de não haver um conceito claro sobre o que seria dignidade humana - opinião compartilhada por outros 12 - e por ser um termo de importância que seria incerta, caracterizando uma "fórmula vazia" para ser preenchida com variados conteúdos" 11 (p. xv).

Para Sandman 13, a dignidade tem elementos que são prescritivos ou avaliativos e elementos que são descritivos. Ele distingue dois tipos de dignidade, que chama de "dignidade humana" e "dignidade contingente", e defende esta distinção para um melhor entendimento do que se quer dizer quando se evoca a "dignidade". "Dignidade humana" tem elementos caracterizadores que se aplicam a todos os seres humanos indistintamente, com um valor muito elevado, distinguindo-os dos demais seres vivos. Já "dignidade contingente", dependendo das características evocadas, não necessariamente poderá ser aplicada a todos os seres humanos. Algumas maneiras pelas quais a "dignidade contingente" fica evidente seriam, por exemplo, por ser autônomo ou racional; ou porque se pode causar temor nos 
outros, autorrespeito, autoestima; ou por desempenhar determinado papel social. Sandman 13 sugere que estas características nem sempre estarão presentes em todos os seres humanos e, portanto, não deveria ser invocada a "dignidade humana" somente porque todos são humanos.

Ainda segundo Sandman, uma das implicações possíveis para os cuidados paliativos se aterem somente à dignidade como um valor muito elevado e igual para todos os seres humanos é que nenhuma morte poderá ser "boa", visto que isso implicaria na perda de um alto valor. Poderia, por conseguinte, justificar esforços em prolongar essa vida, para adiar a perda deste alto valor, e isto seria problemático para os cuidados paliativos. E conclui que "ideias e discussões acerca da dignidade humana não parecem nos conduzir muito longe nesta estrada e, portanto, pareceriam muito inúteis para determinar o que é proporcionar a alguém bons cuidados paliativos (ou outro tipo de cuidado), caso esse cuidado tivesse como finalidade o bem da pessoa que está morrendo" 13 (p. 180).

Assim, a morte com dignidade pode ser mais uma bandeira estratégica ou politicamente adequada, mas será plena de sentido? Afinal, o morrer e a morte não são dignos nem indignos, mas, sim, podese atribuir esta valoração a determinadas práticas de cuidados no fim da vida. Além do mais, tanto o moderno movimento hospice quanto o movimento dos defensores da eutanásia e do suicídio assistido reivindicam uma morte digna, e essa aproximação é desconfortável, especialmente para o movimento hospice 14. Questionamentos como os de Billings ${ }^{15}$, para quem esta seria uma questão excessivamente valorizada pelo movimento hospice e que questiona o quanto, de fato, a questão da dignidade ocupa pacientes que estão morrendo - ele não identifica essa questão como relevante para os pacientes em sua prática de paliativista -, não costuma encontrar muita ressonância, especialmente entre aqueles que acham que há uma resposta afirmativa a estas questões.

\section{Os três grandes campos assistenciais no fim da vida}

Há, no campo do fim da vida, três grandes modelos assistenciais institucionalizados nas sociedades ocidentais contemporâneas: o movimento dos defensores da eutanásia e do suicídio assistido; o moderno movimento hospice - que alberga os cuidados paliativos -; e a biomedicina, entendida, aqui, no sentido dado por Foucault 16, o da estrutura hospitalar tradicional forjada na hierarquia, na observação dos achados clínicos e no poder médico. Agrega-se a esses modelos, em especial ao do movimento hospice, um conjunto de racionalidades médicas, designadas de práticas integrativas ou complementares, que têm propostas de intervenções para o fim da vida semelhantes aos cuidados paliativos e que ganham, cada vez mais, visibilidade e legitimação (p.ex.: medicina ayurvédica, medicina tibetana, medicina chinesa tradicional, medicina antroposófica, entre outras). Esses três campos assistenciais criam um conjunto de características que surgem das intervenções realizadas e de suas consequências, as quais definem o que tem aqui se designado como "modelos de morte", a saber: a eutanásia, fundamento do movimento dos defensores da eutanásia e do suicídio assistido; a kalotanásia, fundamento do moderno movimento hospice; e a distanásia (ou obstinação terapêutica, ou futilidade médica, termo que preferimos utilizar). Aquelas buscam o ideário da boa morte (eu, do grego boa e kalós, do grego boa, virtuosa, nobre), enquanto esta está fundamentada em intervenções persistentes e continuadas, configurando-se em um morrer com sofrimento, a cacotanásia (do grego kakos, sofrimento).

A despeito de em nosso meio utilizar, correntemente, o termo ortotanásia vinculado aos cuidados paliativos, não o identificamos como formativo do modelo de morte dos cuidados paliativos. Foge dos objetivos deste artigo um aprofundamento sobre aspectos conceituais envolvidos na construção desta categoria, porém não são incomuns nos vários textos disponíveis sobre ortotanásia o uso expressões um tanto genéricas e vagas para caracterizá-la, como, entre outros, "morte natural", "processo natural de morte", "curso natural”, "morte normal", "morte como algo natural”, "morte sem interferência da ciência”, "a arte de bem morrer", "morte no seu tempo certo", evidenciando uma problemática questão conceitual, ainda mais se levarmos em consideração as incertezas de quando seria o tempo certo para morrer 17, e diante das obstinadas intervenções biotecnológicas, o que torna a "morte natural" uma raridade em nossa época 18. Ainda que se utilizem princípios de bons cuidados e norteadores dos cuidados paliativos para sua justificativa conceitual, em nosso entendimento, o termo ortotanásia carece dos elementos organizadores e constitutivos do ethos e dos fundamentos antropológicos, históricos e filosóficos do moderno movimento hospice, os quais serão, ainda que brevemente, apresentados 
neste artigo. Por outro lado, temos compreendido que a ortotanásia distingue-se por um conjunto de características que podem ser deflagradas pelo paciente ou que podem ajudar os profissionais de saúde, em especial os médicos, a reverem suas práticas, especialmente diante de condutas obstinadas e persistentes encontrando, nas UTIs, seu locus privilegiado. A ortotanásia, assim, abriria as portas para outras possibilidades assistenciais, o que incluiria - mas não se restringindo a elas - a kalotanásia e, em tese, a despeito de ser legalmente proibido em nosso meio, o modelo institucionalizado de eutanásia/suicídio assistido.

É neste campo de tensões dinâmicas e instáveis que estão inscritas muitas das demandas da bioética do fim da vida, sendo sugeridos, para análise dos conflitos, dentro da visão principialista hegemônica: o princípio da proporcionalidade terapêutica; o princípio do duplo efeito; o princípio da prevenção e o princípio do não abandono 19,20. Essas demandas estão alicerçadas, igualmente, no princípio da autodeterminação (princípio da autonomia e do respeito à autonomia), da qualidade de vida e da dignidade humana - estes três últimos, baluartes do movimento dos defensores da eutanásia e suicídio assistido e do movimento hospice; enquanto, para a futilidade médica, o fundamento ético está intrinsicamente ligado ao vitalismo médico e ao princípio da sacralidade da vida 21.

\section{A morte assistida e medicalizada}

Em relação à "morte assistida e medicalizada", diferentes designações têm sido utilizadas. Por exemplo, eutanásia na Colômbia, Países Baixos, Bélgica e em Luxemburgo; suicídio assistido na Suíça, onde há legislação que permite o suicídio por motivos altruístas desde 1918 22; suicídio assistido por médico nos Países Baixos, Bélgica, Luxemburgo e, no passado, nos Estados Unidos; morte assistida (Austrália); morte com dignidade (Estados Unidos), assistência médica na morte (MAiD - Canadá). Independentemente desses termos, a definição que melhor sustenta, atualmente, o debate acerca de morte assistida e medicalizada, em nosso entendimento, está claramente delimitada no documento da Força-Tarefa da Associação Europeia de Cuidados Paliativos 23 (p. 98), que se manifestou sobre essa questão após três anos de encontros e debates: "Eutanásia é matar sob solicitação e é definida em decorrência de um médico matar intencionalmente uma pessoa pela administração de drogas, a partir de uma solicitação voluntária e competente da pessoa. E: Suicídio assistido por médico é definido como ajuda intencional de um médico [para que] uma pessoa [possa] cometer suicídio, pelo fornecimento de drogas para auto administração, a partir de uma solicitação voluntária e competente da pessoa".

Neste texto não nos ocuparemos das diferentes formas de eutanásia - nem do princípio do duplo efeito, também chamado de eutanásia do duplo efeito, e muitas vezes utilizado como fundamento na tentativa de criminalizar os cuidados paliativos 24 -, as quais, entendemos, colocam juntos, sob a mesma categoria, vários tipos de situações e procedimentos que, ao serem assim reunidos, confundem, trazendo equívocos interpretativos. Tendo o princípio da autodeterminação (princípio do respeito à autonomia) como elemento definidor e determinante, nas sociedades onde estas práticas são socialmente sancionadas e legalmente concebíveis, define-se a eutanásia a partir da solicitação voluntária sustentada temporalmente pelo sujeito que será morto ou que se matará, e não pela ação do agente que o pratica. Dizendo em outras palavras, a solicitação é condição necessária e suficiente para definir eutanásia no debate contemporâneo - pelo menos nessas sociedades -, ao passo que o ato médico é somente condição necessária, mas não suficiente, pois o ato sem o consentimento é crime de homicídio punível na forma da lei.

Também entendemos que a distinção entre a forma ativa e passiva de eutanásia é artificial e confundidora, pois, se a intenção do médico for a de matar o paciente (e isto é condição necessária para definir eutanásia ativa ou passiva), nenhuma diferença faz, do ponto de vista moral, se ele pratica um ato ou se deixa de realizá-lo, já que ambas as formas levam ao seu objetivo, que é matar, sendo a não ação uma forma de ação. E, como a eutanásia legalizada tem a característica de ser tecnicamente rápida, suave e indolor, a forma passiva seria contraintuitiva, pois violaria essas características. Ademais, sentir-se mais ou menos culpado pela ação ou omissão, quando a intenção é matar, não torna alguém moralmente mais ou menos responsável: "Nós aprendemos a pensar que matar é muito pior do que deixar morrer (...) e concluímos, invalidamente, que deve haver algo no matar, em si, que o torna muito pior do que deixar morrer" 25 (p. 114, grifo no original). 
De modo diverso, a decisão médica construída junto ao paciente ou com seus familiares ou representante legal de suspender determinados procedimentos ou tratamentos em um paciente com doença avançada e incurável, por entender que levariam a um aumento do sofrimento ou piora de sua qualidade de vida, decidindo em não postergar uma evolução que irá se consumar, ou de não o submeter a uma intervenção que poderá leva-lo à morte, não pode ser categorizada como uma forma de eutanásia, pois não há a intenção do médico de matar o paciente ao proceder desse modo. Sem a intenção de matar presente no ato, como se pode imputar moralmente ao médico o ato de matar? Teríamos, aqui, que admitir que médicos intencionam matar os pacientes ao assim proceder. Situações como esta, usuais no cotidiano médico, são muitas vezes erroneamente interpretadas como um tipo de eutanásia. Carecem da caracterização de que este ato foi motivado pelo desejo do médico que o paciente morra, não conseguem vincular - e desconsideram este fundamental ponto - a intencionalidade do ato, qual seja, a de querer matar o outro. Trata-se, muito mais, de uma adequação dos meios que levem a um fim sem sofrimento adicional, sem ações que não atingirão seus objetivos, e esta adequação entendemos que se encontra bem delimitada na construção do conceito de ortotanásia. Se não for assim, teremos que forçosamente admitir que os cuidados paliativos estejam fundamentados pela eutanásia passiva e com isso se estaria legitimando essa modalidade de eutanásia nas dezenas de países onde estão instituídos, o que não faz sentido. Defendemos que muitas das questões que poderiam ser enquadradas como prática de eutanásia passiva sejam, de fato, parte integrante do campo da futilidade médica, passíveis de revisão e de decisões conjuntas, sem imputação, pelo menos moral, de dano ao paciente. Em vários contextos de doenças avançadas e em fase terminal, a causa da morte não é a mudança de procedimentos que visam agregar qualidade de morte e que são parte de um plano de cuidados construído com o paciente e seus familiares, mas a evolução inexorável da doença de base. Como bem coloca Callahan 26, confunde-se, aqui, causalidade com culpabilidade.

Atados a um ordenamento jurídico que criminaliza sua prática em nosso meio, temos dificuldade em avançarmos na discussão sobre essa complexa prática assistencial médica, a eutanásia, e ficamos discutindo as confundidoras classificações estabelecidas. Uma parte substancial da literatura bioética nacional está, neste ponto, vinculada ao ordenamento jurídico vigente, o qual deveria ser uma das últimas instâncias na organização legisladora, consequência da ampla e profunda discussão na sociedade acerca deste específico modelo de intervenção médica. Não estamos querendo dizer, com isto, que somos, em tese, a favor ou contra a eutanásia/suicídio assistido, mas estamos defendendo que a sociedade discuta abertamente esse modelo assistencial - o de matar ou ajudar a morrer sob solicitação sustentada de quem sofrerá o ato -, sem trazer para este campo de debates os diversos tipos classificatórios de eutanásia e os dispositivos jurídicos que a partir deles consolidaram entendimento normativo em nosso país. Estamos, por conseguinte, atrasados no debate contemporâneo a respeito da eutanásia/suicídio assistido há, pelo menos, 30 anos, já que esse intenso debate acontece na Europa e nos Estados Unidos desde a década de 1990. Podemos inferir a evolução da discussão nestes países quando lemos manifesto de um importante teólogo católico alemão defendendo abertamente o direito à eutanásia para o idoso que perdeu sua autonomia, deixando manifesta essa vontade 27 .

Nesse sentido, as diretivas antecipadas de vontade são recente instrumento de avanço disponível em nosso meio 28 , a despeito de não respaldarem solicitação de eutanásia, o que o torna, por outro lado, limitado na sua fundamentação pelo princípio do respeito à autonomia, pois cerceia esse princípio em sua abrangência maior, qual seja, a de que o paciente se torne sujeito de sua vida e de sua morte, essencial aspecto de sua existência.

Inicialmente somente definida para pacientes com doenças avançadas e terminais, progressivas e em atividade, a eutanásia/suicídio assistido por médico já é contemplada para pacientes em que a doença não é o critério de inclusão, sendo critério também, o sofrimento psicológico ou existencial o que abre as portas para importante e complexa flexibilização -, por exemplo, depressão intratável por causar intenso sofrimento. Ou para aquilo que tem sido designado como "suicídio racional no idoso", cujo caso mais recentemente divulgado na mídia foi o do cientista britânico David Goodall, de 104 anos, que viajou da Austrália para a Suíça para ser morto, pois sua vida não tinha mais sentido. No suicídio racional, o idoso longevo conclui que viveu sua vida, realizou o que tinha que realizar, conquistou e perdeu o que tinha que conquistar e perder, que não há, para ele, mais nada a ser feito no presente e no futuro, perdeu suas referências de relações: "passei do prazo de validade" (frase dita por um 
paciente idoso centenário). Não há, nesse tipo de solicitação, doença que o levará à morte, mas constatação e desejo de terminar com a vida e o entendimento de que ele tem o direito de ser assistido nesse desejo. A vida do idoso longevo, nessas circunstâncias, perdeu significado, seu sentido racional de ser, conforme Goodall: "quão insatisfatória minha vida é aqui, insatisfatória em quase todos os aspectos. Quanto mais cedo terminar, melhor. (...) Eu estou dizendo adeus o tempo todo. (...) Deve-se ser livre para se usar o resto de sua vida como quiser. (...). Se alguém escolhe se matar, isto é justo. Não acho que mais alguém deva interferir" 29.

Pode ser legítimo que um idoso longevo que vive nestsas circunstâncias existenciais possa querer se matar, a despeito do quanto seu ato possa ser trágico, bom ou ruim, afinal, pessoas se matam. Dependendo de onde buscamos força e confiança para existir, responderemos de diferentes maneiras, e uma dessas maneiras pode ser o suicídio. É de Camus a constatação, ao refletir sobre o sentimento do absurdo da relação existencial de transcendência do ser humano divorciado de seu cenário: "Só há um problema filosófico verdadeiramente sério: é o suicídio" 30 (p. 13).

A questão que aqui se coloca, no debate da eutanásia, é: por que necessitamos do outro para fazê-lo? E, se necessitamos, quem o fará? O médico? No suicídio assistido, a interferência médica é mais distante, ainda que ele participe do ato e esteja vinculado ao acontecimento, pois sabe aquilo que está fazendo - prescrevendo medicamentos e dando suporte e orientações -, oferece os meios para a pessoa se matar. No caso da eutanásia, uma questão que nos parece relevante não é se o princípio da autodeterminação deva ser respeitado e levado às últimas consequências, mas o que acontecerá com a sociedade que, para aceitar um direito legalmente estabelecido do paciente, qual seja, o de ser morto, para aceitar essa determinação de sua vontade, estabelece um direito ao médico: o direito de matar. A sociedade, ao proceder desse modo, legitima que médicos possam matar, dentro de suas atividades cotidianas de assistência. O dever médico de matar se imporá, já que ele é quem poderá matar (ainda que muitas vezes o enfermeiro é quem realiza o ato em si, que pode ser recusável pelos dois, pela cláusula da objeção de consciência), e esse dever surge a partir de um direito do paciente, reconhecido e sancionado juridicamente. $\mathrm{O}$ dever médico de matar legitimará um direito médico a matar. Devemos, entretanto, reconhecer que a atividade médica é secularmente vinculada a práticas nas quais os médicos agem para salvar vidas, curar doenças e mitigar o sofrimento em favor da vida. Com a descriminalização da eutanásia, abrem-se as portas para legitimar que médicos possam matar. Como mantermos socialmente a relação médico-paciente sustentada na crença e na confiança de que o médico estará agindo nos melhores interesses do paciente, uma vez que esses melhores interesses são compreendidos em favor da preservação da vida? Como evitaremos uma ladeira escorregadia - independentemente do fato de que a ladeira sempre poderá ser invocada, criando um cenário de futuro catastrófico -, onde os médicos possam decidir matar, abrindo possibilidades para que outras formas de interesses possam interferir no ato médico secularmente vinculado a uma prática curativa e não maleficente (primum non nocere)? Ao matar um inocente, entendido como alguém cujos atos não atentem contra a integridade física do outro, o ato médico em si será moralmente menos importante por estar amparado na lei? Estas e outras questões têm sido identificadas nos países onde esta prática assistencial é descriminalizada, e devemos estar abertos para discuti-las 31,32 .

\section{A futilidade médica e o tonel das Danaides}

Em relação à futilidade médica (do latim futilis, que deixa escapar o que contém), a medicina contemporânea atingiu um desenvolvimento técnico tão impressionante que os médicos tendem a considerar um imperativo sua incorporação - e, consequentemente, sua utilização no dia a dia -, correndo-se constantemente o risco de reivindicá-lo como sendo, também, uma exigência ética. Ou seja, o desenvolvimento tecnológico a serviço da medicina se impôs com tanta força, devido ao estupendo desenvolvimento nesta área e, talvez, de um modo irreversível, que fez surgir no médico certo desconforto ao não utilizar essa tecnologia, emergindo uma espécie de imperativo tecnológico na prática médica. Com isso, o que pode ter ocorrido é uma inversão da relação entre medicina e tecnologia: não mais esta a serviço daquela, mas, ao contrário, a medicina a serviço da tecnologia e, portanto, ao sentiremse compelidos a usar uma técnica disponível, os médicos estariam, de fato, confundindo uma possibilidade de agir, propiciada pela técnica, com um dever de agir, que só pode tirar sua justificação dentro de um sistema de valores, e não de uma mera relação pragmática de otimização entre meios e fins. 
Estamos nos referindo especificamente a um modelo de intervenções que se caracteriza pela "ausência de um propósito útil ou de um resultado útil em um procedimento ou intervenção diagnóstica ou terapêutica. Trata-se da situação de um paciente na qual a condição não será melhorada pelo tratamento ou, na qual, o tratamento mantém uma permanente inconsciência, ou não pode acabar com a dependência de cuidados médicos intensivos" 33 .

Moller 34 busca na formação atual do médico as possíveis explicações para seu distanciamento do paciente com doença avançada; para ele, isso se deve muito mais ao modo como essa formação ocorre do que necessariamente por uma questão de caráter pessoal do médico. Moller pondera que tanto o médico quanto o estudante de medicina estão sobrecarregados por uma demanda de conhecimentos técnicos, continuamente ensinados como determinantes para suas formações, o que os levaria a dedicarem muito tempo de seus estudos a esse domínio, em detrimento de outros conhecimentos, com pouco tempo para o conhecimento do paciente e de sua biografia. Os médicos precisam e devem conhecer as doenças, sendo treinados dentro de um contexto de intervenções tecnológicas heroicas, com significativa dificuldade de aceitarem a não intervenção ou a interrupção de um tratamento. A consequência disso seriam sucessivas intervenções, com o prolongamento do tratamento e o paciente morrendo cercado por máquinas e tubos. Acrescente-se a isso a inabilidade do médico para ouvir e responder às demandas do paciente e de seu entorno; a comunicação inadequada, principalmente para dar uma notícia ruim; e a abordagem insatisfatória da dor e do sofrimento do paciente, configurando-se um ambiente difícil de inter-relações entre o médico, o paciente e a família deste.

Deve-se também considerar que muitos estudantes de medicina e médicos creem que, diante de uma doença avançada ou terminal, "há muito pouco a se fazer", ou pior, que "não há nada para se fazer"; eles não conseguem, portanto, se interessar pelo paciente, pois perderam o interesse pela doença, pela resposta ao tratamento. Esse desinteresse talvez se deva, em parte, ao fato de que a medicina, tal como a concebemos hoje, foi construída com base em uma racionalidade que se ocupou e que se interessa intensamente pela doença, e das observações clínicas sobre um conjunto cada vez maior de intervenções realizadas. Independentemente das causas, o cenário que surge é um cenário de desapropriação e importante medicalização do processo do morrer, e de isolamento do paciente, com uma morte em sofrimento desproporcional. Diz-se "desproporcional" visto que o sofrimento é inevitável para a condição humana e que, dentro dessa inevitabilidade, há um limite para o sofrimento, o qual independe da presença ou não de dor.

Este é o cenário que vige nos hospitais tradicionais, um cenário de práticas que, diante da inexorabilidade da doença, que avança e está levando o paciente à morte, não atingem os objetivos aos quais se destinam, que seriam recuperar a saúde e oferecer qualidade de vida. De fato, constituem um cenário de práticas fúteis, que melhoram as partes sem trazer benefício ao todo, em uma incessante e persistente conduta que pretende ser beneficente - e aqui reside a confusão e a dificuldade de parar ou de mudarem-se os procedimentos -; porém, em essência, práticas maleficentes, pois não agregam os benefícios para a recuperação de uma vida plena, não devendo ser essas práticas confundidas com intervenções impossíveis (p.ex.: massagem cardíaca em paciente em choque hipovolêmico sem reversão da hipovolemia) ou com atos em tese possíveis, mas extremamente complicados (p.ex.: gravidez fora do útero) 35 .

Como no mito grego das Danaides, o médico condena-se a repetir seus procedimentos indefinidamente, mas cujos resultados se esvaem, como acontece com o intenso trabalho das Danaides que, condenadas por seus pecados, somente se libertariam de sua condição se conseguissem encher seus vasos furados com água, o que era uma atividade fútil. Daí a expressão "tonel das Danaides" metaforicamente significar um esforço permanente, visto não terminar, repetido e sem conseguir atingir seus objetivos. Paradoxalmente, o hospital, socialmente identificado pela ideologia do resgate, continua a ser a via final de encaminhamento dos pacientes com doenças avançadas, ou seja, o lugar considerado apropriado para receber pacientes gravemente adoecidos, muitos deles em fase terminal. E passa a ser também o espaço onde se organizam os cuidados paliativos, a despeito de não terem surgido nesse ambiente, dialogando cada vez mais dentro de um cenário de intervenções continuadas e persistentes. 


\section{Sobre a dimensão do cuidado e sua relação com o desenvolvimento das virtudes}

Talvez, diante dessa realidade, se tratasse de o médico poder compreender a importância do "cuidado", de conseguir compreender e responder adequadamente à vulnerabilidade em que vive a pessoa que adoece. Em outras palavras, tornando-se sensível e conseguindo, de modo empático, perceber a fragilização do momento vivido pelo paciente, fragilização esta imposta por seu adoecimento e pelas sucessivas tentativas de tratamento curativo, muitas vezes com uma evolução inexorável e esmagadora. Como bem sintetizou Callahan 36 (p. 144):"O cuidado deve sempre ser prioritário sobre a cura, pela mais óbvia das razões: nunca há qualquer certeza de que nossas enfermidades possam ser curadas, ou nossa morte evitada. Eventualmente, elas poderão e devem triunfar. Nossas vitórias sobre nosso adoecimento e [sobre a] morte são sempre temporárias, mas nossa necessidade de suporte, de cuidados, diante deles, é sempre permanente".

Aqui, deve-se ponderar acerca da dicotomia entre cura e cuidado, a qual parece justificar, mesmo entre os defensores dos cuidados paliativos, um "tudo fazer" quando se está em busca da cura, como se este "tudo fazer" justificasse um "não cuidar", ou - o que é pior - como se ele subentendesse um "não cuidar". Nesse tipo de proposição reside uma importante segmentação de ações distintas artificialmente, com consequências danosas especialmente ao paciente. Essa segmentação, ao mesmo tempo, justifica condutas de cura sem cuidado, o que só reforça a fragmentação implicada por essa dicotomia, a qual está em conformidade com um desejo social que pressiona o médico: a "cura" a qualquer preço. Assim, vende-se a ilusão de que as doenças têm cura, quando a maior parte das doenças é crônica, o que define a não existência de cura. Essa fragmentação leva também à danosa consequência social de muitas vezes eximir o médico, em especial o especialista, de qualquer responsabilidade pelas consequências advindas com as sucessivas tentativas de tratamento curativo e, em conformidade com isso, sem a necessidade de atuar cuidando, visto que ele não cuida; ele pretensamente cura, considerando que suas ações são tecnicamente corretas e bem indicadas e, portanto, livres das sanções legais que possa vir a sofrer. Legitima-se socialmente que o especialista se exima, por conseguinte, de dar seguimento aos cuidados na fase final da doença, em que o problema já não é mais dele, visto que ele, supostamente, cura, não cuida. Como disse, certa vez, a filha de uma paciente que estava morrendo de câncer: "ela tem um oncologista, mas agora ele disse que não é mais com ele, e por isso trouxemos ela aqui, ele não tem mais o que tratar". O problema não é mais do especialista. De quem será, então?

A prioridade do cuidado sobre a cura deve ser compreendida dentro de um modelo médico em que a cura deva ser exercida com cuidado, aqui entendido como amparo, acolhimento e proteção. A complexidade dessa discussão reside no fato de que qualquer médico que assiste uma pessoa adoecida está, obviamente, cuidando, mas esta ação está subsumida à busca da cura. Cura e cuidado separados dão, assim, a dimensão dos problemas que eximem o ato médico que cura, de cuidar.

A solução que tem sido apresentada para complementar a "cura sem cuidado" do médico, com o "cuidado sem a cura", pode ser contemplada com a criação de uma nova especialidade médica - a medicina paliativa - que forma médicos que, em princípio, cuidam de quem morre, não estando a serviço da cura. Todas as esperanças passam, uma vez que não é possível mais curar uma doença, a ser depositadas nos "especialistas do conforto". Como, no cotidiano da atividade médica, isso se integrará? Como se fará essa transição, dentro de um modelo vigente de valorização de especialistas, e a que preço para o paciente?

Este é o papel do terceiro grande campo assistencial no fim da vida, os cuidados paliativos, que pretendem, na busca da transcendência na jornada de luta do paciente, da doença como sentido, da recepção incondicional do estranho que chega (o paciente com doença avançada) e do nãoabandono, construir um "jeito hospice de cuidar", um "jeito hospice de morrer", abarcando incondicionalmente esse momento de vida singular no umbral da morte, processo de transformações e de aprendizado: "A doença terminal não deveria ser encarada como uma intrusão na vida; ela é parte da vida e pode ser um tempo de ampliação da maturidade e [de] aprofundamento na experiência espiritual para todos os envolvidos. É nosso trabalho como médicos ajudar a ser assim" 37 (p. 21).

A dimensão do cuidado levada a seu máximo, na aceitação do outro e no acolhimento incondicional, é a proposta dos cuidados paliativos. A boa morte dos cuidados paliativos nasce tendo como fundamento ético o desenvolvimento de determinadas virtudes a partir do seu aperfeiçoamento contínuo, que são concretizadas a partir do outro, do estranho que chega, que está de passagem, o paciente diante da morte. Como nos ensina a fundadora do moderno movimento hospice, Cicely Saunders 38 (p. 
165): "o lugar [onde poderemos] achar sentido está, frequentemente, no ordinário, no continuamente repetitivo e [no] insignificante. Um verdadeiro encontro entre duas pessoas é uma dádiva que surge espontaneamente no meio destes atos".

Tal ethos nos parece mais adequado do que um conjunto de deveres internalizados, um código de regras morais que ressoam dentro do agente moral, mas são exteriores a este agente: percepção do outro, compaixão, consideração ao outro, cooperação, coragem, benevolência (disposição interna para praticar o bem, diferentemente de um dever fazer o bem, a beneficência), paciência, prudência, respeito, tolerância, entre outros atributos virtuosos são, em nosso entendimento, imprescindíveis para acolher incondicionalmente o outro. Atos movidos por genuína compaixão formam o estofo onde pode germinar o acolhimento ao paciente, ajudando-o em sua individual jornada de luta no umbral da morte.

As características constitutivas desse modelo específico de assistência no fim da vida revivem antigos processos de ritualização do morrer - o que Walter 39 chamou de revivalismo tanatológico -, incorporando em sua fundamentação a palavra latina hospice - derivada do latim hospes, "aquele que recebe o outro" -, que tem a mesma origem semântica que hospitalidade, aqui compreendida como incondicional recepção do Outro, no sentido levinasiano desse estranho 40, este estranho que chega, que pede acolhida e um teto no limiar da morte; e tendo, igualmente, a mesma origem semântica que a palavra latina hospitium, ou seja, um sentimento caloroso de pertencimento que se desenvolve entre o hospedeiro, aquele que acolhe, e o hóspede, aquele que chega 41. Esses elementos constitutivos do edifício filosófico e ético do moderno movimento hospice podem ser identificados no emblema do Saint Christopher's Hospice (Londres, Inglaterra), seu centro irradiador e de difusão mundial: o ethos cristão, identificado na palavra Cristóvão - "aquele que carrega Cristo" - e no bastão que enraíza e que dá frutos no concreto; a jornada de luta, a travessia entre duas margens sólidas, a terrestre e a dimensão do além-morte como o outro lado da travessia, em um período de significativas turbulências em águas revoltas; a necessidade de amparo, de proteção, o estranho que chega e que é cuidadosamente transportado nessa trajetória; o Outro, o curador da ferida do cuidador, aquele que dá o sentido para o cuidado; e o potencial processo de crescimento espiritual para todos os envolvidos.

Fundamentada na ritualização das cenas de despedida, na busca de um sentido transformador da doença e dentro desse ethos cristão, a kalotanásia - a boa morte do moderno movimento hospice - e seu processo dinâmico são deflagrados por quem está morrendo e colocados em prática, se assim for possível, como alicerce de um modelo de morte que pretende acolher, amparar, proteger e dar sentido ao processo de morrer do paciente no limiar de sua existência, no umbral da morte. Apresenta-se, assim, como um saber-fazer em contraponto ao modelo de morte rápida, suave e indolor representado pela boa morte do movimento dos defensores da eutanásia e do suicídio assistido. Pretende, outrossim, ser importante via de realizações e de cuidados em um sistema de saúde centrado na ideologia do resgate, presente nos hospitais gerais, no qual, com bastante frequência, há uma prática médica no fim da vida que se caracteriza ou por excessivas intervenções ou por abandono, ou pelas duas situações ao mesmo tempo.

\section{Considerações finais}

A construção de modelos adequados de assistência no fim da vida tem se mostrado imperativa, com impacto sobre o paciente, seu entorno e sobre a organização e alocação de recursos humanos, tecnológicos e econômicos no sistema de saúde. Pacientes com doenças avançadas, progressivas e terminais são frequentemente admitidos em hospitais, estruturados dentro de uma ideologia do resgate, a qual se mostra inadequada, desproporcional e maleficente, a despeito de benefícios pontuais. Um avanço concreto na organização desses modelos de morte em nossa realidade deverá incluir a revisão conceitual e o aprofundamento no debate sobre o entendimento contemporâneo da eutanásia e do suicídio assistido, bem como de seus desdobramentos. Igualmente, é necessário que haja efetiva política nacional que alicerce a prática dos cuidados paliativos a ser estabelecida em cenários diversificados, como é o caso do Brasil, fundamentada em um modelo de boa morte que se propõe acolher incondicionalmente o paciente e seu entorno, em um cenário de potenciais transformações a todos os envolvidos. 


\section{Informação adicional}

ORCID: Ciro Augusto Floriani (0000-0002-77356887).

\section{Agradecimento}

À professora Dra. Maria Eliana Labra, por sua leitura e sugestões no campo das políticas públicas sobre o tema.

\section{Referências}

1. Chochinov HM. Dying, dignity, and new horizons in palliative end-of-life care. CA Cancer J Clin 2006; 56:84-103.

2. Walter T. Historical and cultural variants on the good death. BMJ 2003; 327:218-20.

3. Ariès P. O homem diante da morte. v. II. Rio de Janeiro: Francisco Alves; 1982.

4. Ariès P. História da morte no Ocidente. Rio de Janeiro/São Paulo: Ediouro; 2002.

5. Elias N. A solidão dos moribundos. Envelhecer e morrer. Rio de Janeiro: Jorge Zahar; 2001.

6. Kübler-Ross E. Sobre a morte e o morrer. São Paulo: Martins Fontes; 1987.

7. Saunders C. In Britain: fewer conflicts of conscience. Hastings Cent Rep 1995; 25:44-5.

8. Clark D. Between hope and acceptance: the medicalisation of dying. BMJ 2002; 324:905-7.

9. Higginson IJ, Hall S. Rediscovering dignity at the bedside. BMJ 2007; 335:167-8.

10. Chochinov HM. Dignity. Dignity? Dignity! J Palliat Med 2008; 11:674-5.

11. Bayertz K. Sanctity of life and human dignity. In: Bayertz K, editor. Sanctity of life and human dignity. Dordrecht: Kluwer Academic Publishers; 1996. p. xi-xix.

12. Johnson PRS. An analysis of "dignity". Theor Med Bioeth 1998; 19:337-52.

13. Sandman L. What's the use of human dignity within palliative care? Nursing Philosophy 2002; 3:177-81

14. Campbell CS, Hare J, Matthews P. Conflicts of conscience: hospice and assisted suicide. Hastings Cent Rep 1995; 25:36-43.

15. Billings JA. Dignity. J Palliat Med 2008; 11:138-9.

16. Foucault M. O nascimento da clínica. Rio de Janeiro/São Paulo: Forense Universitária; 1998.

17. Siqueira-Batista R, Schramm FR. Conversações sobre a "boa morte": o debate bioético acerca da eutanásia. Cad Saúde Pública 2005; 21:111-9.

18. Sandman L. Should people die a natural death? Health Care Anal 2005; 13:275-87.

19. Quill TE, Dresser R, Brock DW. The rule of double effect - a critique of its role in endof-life decision making. N Engl J Med 1997; 337:1768-71

20. Taboada P, Ugarte AR, Bertucci MV. Dimensión ética del morir. ARS Medica 2000; 2:3144.

21. Mori M. A bioética: sua natureza e história. Humanidad 1994; 9:333-41.

22. Hurst SA, Mauron A. Assisted suicide and euthanasia in Switzerland: allowing a role for non-physicians. BMJ 2003; 326:271-3. 
23. European Association of Palliative Care Task Force. Euthanasia and physician-assisted suicide: a view from an EAPC Ethics Task Force. Eur J Palliat Care 2003; 10:63-6.

24. Gilbert J, Kirkham S. Double effect, double bind or double speak? Palliat Med 1999; 13:365-6.

25. Rachels J. The end of life: euthanasia and morality. Oxford/New York/Melbourne: Oxford University Press; 1986.

26. Callahan D. When self-determination runs amok. In: Helga K, Singer P, editors. Bioethics: an anthology. Oxford: Blackwell Publishers Ltd.; 1999. p. 327-31.

27. Küng H. Uma boa morte. Lisboa: Relógio D’Água Editores; 2017.

28. Conselho Federal de Medicina. Resolução CFM no 1.995/2012. Dispõe sobre as diretivas antecipadas de vontade dos pacientes. Diário Oficial da União 2012; 31 ago.

29. Hamlyn C. 104-year-old academic David Goodall to travel to Switzerland for voluntary euthanasia. ABC News 2018; 30 abr. https:// www.abc.net.au/news/2018-05-01/davidgoodall-to-travel-to-switzerland-for-volun tary-euthanasia/9714292.

30. Camus A. O mito de Sísifo: ensaio sobre o absurdo. Lisboa: Livros do Brasil; s.d.

31. Downie RS, Randall F. Palliative care ethics: a companion for all specialties. Oxford: Oxford University Press; 1999.

32. European Institute of Bioethics. Euthanasia in Belgium: 10 years on. http://www.ieb-eib.org/ en/pdf/20121208-dossier-euthanasia-in-bel gium-10-years.pdf (acessado em 27/Set/2015).
33. National Library of Medicine. Medical futility. https://www.ncbi.nlm.nih.gov/mesh/?term= medical+futility (acessado em 08/Jun/2021).

34. Moller DW. Death, societal attitudes toward. In: Callahan D, Singer P, Chadwick R, editors. Encyclopedia of applied ethics. v. 1. San Diego: Academic Press; 1998. p. 735-45.

35. Schneiderman LJ, Jecker NS, Jonsen A. Medical futility: its meaning and ethical implications. Ann Intern Med 1990; 112:949-54.

36. Callahan D. What kind of life: the limits of medical progress. Washington DC: Georgetown University Press; 1990.

37. Twycross R. The dying patient. London: CMF Publications; 1978.

38. Saunders C. Dying they live: St. Christopher's Hospice. In: Feifel H, editor. New meanings of death. New York: McGraw-Hill; 1977. p. 15379 .

39. Walter T. Revival of death. London/New York: Routledge; 1994

40. Lévinas E. Entre nós: ensaios sobre a alteridade. Petrópolis: Editora Vozes; 2005.

41. Floriani CA, Schramm FR. How might Levinas' concept of the other's priority and Derrida's unconditional hospitality contribute to the philosophy of the modern hospice movement? Palliat Support Care 2010; 8:215-20. 


\section{Abstract}

The article discusses contemporary societies' three institutionalized fields in end-of-life care and their respective models of death: euthanasia/assisted suicide; medical futility; and kalothanasia, the basis for the modern hospice movement. The article also analyzes how these models impact patients' lives and the conceptual weakness of some traditionally used banners such as that of human dignity. It also comments on orthothanasia, a widely used concept in the Brazilian bioethical literature, as well as rational suicide in the elderly. Questions are posed for the bioethical debate on the need to rethink some postulates, especially pertaining to euthanasia. Finally, the article presents and analyzes the ethical and philosophical basis for kalothanasia and its implications for the organization of good practices in end-of-life care.

Bioethics; Attitude to Death; Medical Futility; Euthanasia; Palliative Care

\section{Resumen}

Este artículo discute los tres campos asistenciales institucionalizados en sociedades contemporáneas para los cuidados al fin de la vida, y sus respectivos modelos de muerte: eutanasia/suicidio asistido; futilidad médica; y kalotanasia, fundamentada en el moderno movimiento hospice. Analiza, también, de qué modo estos modelos impactan en la vida de los pacientes, así como la fragilidad conceptual de algunas de las banderas tradicionalmente utilizadas, como la de la dignidad humana. Se realizan, también, consideraciones sobre la ortotanasia, concepto muy utilizado en la literatura bioética nacional, así como respecto al suicidio racional en ancianos. Además, en nuestro medio, se proponen cuestiones para el debate bioético acerca de la necesidad de que sean repensados algunos postulados, especialmente, aquellos que se refieren a la eutanasia. Por último, presenta y analiza la base ética y filosófica de la kalotanasia, y sus implicaciones para la organización de buenas prácticas de cuidados durante el fin de la vida.

Bioética; Actitud Frente a la Muerte; Inutilidad Médica; Eutanasia; Cuidados Paliativos

Recebido em 07/Set/2020

Versão final reapresentada em 08/Jun/2021

Aprovado em 25/Jun/2021 